\title{
Nocturnal Leg Cramps and Chronic Obstructive Pulmonary Disease
}

\author{
Sevilay Hintistan* and Burcu Cuvalci RN \\ ${ }^{1}$ Karadeniz Technical University Health Sciences Faculty, Nursing Department, Trabzon, Turkey \\ ${ }^{2}$ Burcu Cuvalci RN, Karadeniz Technical University Health Sciences Faculty, Nursing Department, Trabzon, Turkey
}

Submission: August 20, 2018; Published: September 07, 2018

*Corresponding author: SevilayHintistan RN, Karadeniz Technical University Health Sciences Faculty, Nursing Department, Trabzon, Turkey, Tel: 0090046223004 76; Email: sevilayhindistan@gmail.com

\begin{abstract}
Chronic obstructive pulmonary disease is a health problem with high morbidity and mortality. Long term inactivity, corticosteroid use, insufficient nutrition, decreased anabolic hormone level, hypoxemia and electrolyte imbalance may lead to nocturnal leg cramps through causing peripheral muscle dysfunction. Nocturnal leg cramps impair sleep pattern and quality through causing severe leg pain and fatigue. Impaired structure and quality of sleep increase exacerbations, disease severity and cost, decrease overall wellness and quality of life together with pain and fatigue. Control of nocturnal leg cramps would be effective in management of chronic obstructive pulmonary disease.
\end{abstract}

Keywords: Nocturnal Leg Cramp; Chronic Obstructive Pulmonary Disease; Sleep; Cramp

Abbreviations: COPD:Chronic Obstructive Pulmonary Disease

\section{Introduction}

Chronic obstructive pulmonary disease (COPD) is a common, preventable and treatable disease usually caused by exposure to harmful particles or gases, characterized by airway and/ or alveolar anomalies-related permanent airflow restriction and respiratory symptoms [1]. Global Initiative for Chronic Obstructive Lung Disease has reported number of patients with COPD as 384 million and global prevalence as $11.7 \%$ in 2010 [1]. COPD prevalence is predicted to increase during next 30 years and number of COPD-related deaths is predicted to exceed 4.5 million until 2030 [2].Nocturnal leg cramps are defined as "intensive and unintentional contractions which abruptly emerge during night, characterized by sudden pain episodes in thigh, calf of the leg or foot" and among sleep-related movement disorders [3-5]. Leg cramp which is also defined as spasm, contraction, pain, strain, tetany, swelling or muscle paralysis is a painful symptom and may take about nine minutes [6]. National Health and Nutrition Examination Survey has detected that 30\% of individuals experience nocturnal leg cramps and nocturnal leg cramps are associated with chronic diseases like emphysema, bronchitis and asthma in a study investigating nocturnal leg cramps in adults between 2005-2006 [7].

\section{Discussion}

Nocturnal leg cramps are reported to be associated with many potential etiologic factors [3,6]. Respiration and gas exchange are negatively influenced in COPD patients due to airway resistance and obstruction, oxygen saturation decreases, hypoxia, hypercapnia develop and inspiration capacity decreases $[8,9]$. Chronic hypoxia reduces muscle mass and surface area of type I fibers and decreases oxidative capacity of the muscle [10]. Low oxidative capacity increased pro-inflammatory cytokines, systemic inflammation, chronic inactivity, systemic use of corticosteroids, nutritional imbalance, low anabolic hormone level, hypoxemia and electrolyte disorders facilitate peripheral muscle dysfunction which could precipitate nocturnal leg cramps in COPD $[10,11]$. Albuterol, levabuterol, beta-agonists and steroids are reported to lead to leg cramps $[3,6]$. In addition, chronic use of steroids precipitate dysfunction through leading to muscle fatigue, necrosis and lactic dehydrogenase level elevation in COPD patients [10,12]. Furosemide, beta- 2 agonists and theophyline which are used in COPD treatment contribute to nocturnal leg cramp development by leading to severe side effects like hypo-kalemia, hypo-calcemia and hypomagnesemia[10,13]. Oboler et al. report that $63 \%$ of the patients who admit to outpatient clinic due to leg cramps have hypokalemia[14]. The imbalance between calorie intake and energy consumption, and malnutrition in COPD is reported to reduce muscle mass through reducing protein synthesis and lead to muscle fatigue $[10,11]$.

Nocturnal leg cramps reduce sleep pattern and sleep quality, impair wellness and quality of life through leading to awakening $[5,15]$. Acute phase of leg cramps may go with recurrent episodes 
of a couple of hours and permanent pain and is accepted as a cause of secondary sleep disorders [6]. In the study of Hawke et al., individuals who experience nocturnal leg cramps are reported to experience sleep disorders more, sleep more at night and less during daytime and have sleepiness during day time [15]. Sleep deprivation leads to impaired pulmonary functions through causing temporal reductions in forced vital capacity and the volume at 1 st second of expiration and may lead to exacerbations in COPD [16]. Pain, tenderness and discomfort caused by nocturnal leg cramps which last for several seconds or minutes continue up to a couple of hours and even last until daytime $[3,17]$. Redmond et al. report that muscle cramps reduce physical role and functioning, overall health and activity level, quality of life and increase pain [18].

\section{Conclusion}

Nocturnal leg cramps which could prevent maintenance of a quality sleep that is of vital importance in COPD is evaluated as a challenging nocturnal symptom due to obscure diagnosis and treatment $[6,8,9]$. It is seen that nocturnal leg cramps which could frequently develop in COPD patients are not addressed sufficiently in literature and thereby proper interventions are not planned. In addition, patients are estimated not to report nocturnal leg cramps enough although they impair daily living activities. Whereas interventions may be made for reduction/ elimination of nocturnal leg cramps which develop in COPD patients. Prevention of nocturnal leg cramps which are among the causes which impair quality of sleep, quality of life is of vital importance for disease management.

\section{References}

1. Global Initiative for Chronic Obstructive Lung Disease (GOLD), Global Strategy for the Diagnosis, Management and Prevention of COPD (2018).

2. Global Initiative for Chronic Obstructive Lung Disease (2017) Global Strategy for Diagnosis, Management, and Prevention of Chronic Obstructive Pulmonary Disease.

3. Butler JV, Mulkerrin EC, Okeeffe ST (2002) Nocturnal Leg Cramps in Older People. Postgrad Med J 78(924): 596-598.

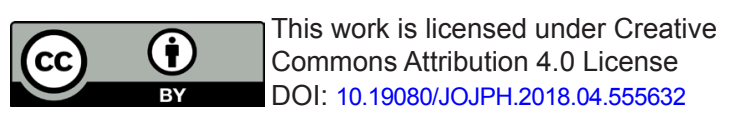

4. Karadag M (2007) Classification of Sleep Disorders (ICSD-2). Turkiye Klinikleri Arch Lung 8(4):88-91.

5. Hallegraeff J, de Greef M, Krijnen W, van der Schans C (2017) Criteria in Diagnosing Nocturnal Leg Cramps: A Systematic Review. BMC Family Practice 18(1): 29

6. Allen RE, Kirby KA (2012) Nocturnal leg cramps. Am Fam Physician 86(4): 350-355.

7. Grandner MA, Winkelman JW (2017) Nocturnal Leg Cramps: Prevalence and Associations with Demographics, Sleep Disturbance Symptoms, Medical Conditions, and Cardiometabolic Risk Factors. PloS one 12(6): e0178465.

8. Stege G, Vos PJE, van den Elshout FJ, Dekhuijzen PR, van de Ven MJ, et al. (2008) Sleep, Hypnotics and Chronic Obstructive Pulmonary Disease. Respiratory Medicine 102(6):801-814.

9. Agusti A, Hedner J, Marin JM, Barbé F, Cazzola M, et al. (2011) NightTime Symptoms: A Forgotten Dimension of COPD. Eur Respir Rev20(121):183-194.

10. Breunung L, Roberts M (2011) Peripheral Muscle Dysfunction and Chronic Obstructive Pulmonary Disease. British Journal of Hospital Medicine 72(1): 17-21.

11. Roca M, Mihăescu T (2012) Peripheral Muscle Dysfunction in Chronic Obstructive Pulmonary Disease. Pneumologia (Bucharest, Romania)61(3): 178-182.

12. Decramer M, De Bock V, Dom R (1996) Functional and Histologic Picture of Steroid-Induced Myopathy in Chronic Obstructive Pulmonary Disease. AJRCCM 153(6): 1958-1964.

13. Alamoudi OS (2001) Electrolyte Disturbances in Patients with Chronic, Stable Asthma: Effect of Therapy. Chest 120(2): 431-436.

14. Oboler SK, Prochazka AV, Meyer TJ (1991) Leg Symptoms in Outpatient Veterans. West J Med 155(3):256-259.

15. Hawke F, Chuter V, Burns J (2013) Impact of Nocturnal Calf Cramping on Quality of Sleep and Health-Related Quality of Life. Qual Life Res 22(6):1281-1286.

16. Phillips BA, Cooper KR, Burke TV (1987) The Effect of Sleep Loss on Breathing in Chronic Obstructive Pulmonary Disease. Chest 91(1):2932.

17. Monderer RS, Wu WP, Thorpy MJ (2010) Nocturnal Leg Cramps. Neurol Neurosci Rep 10(1): 53-59.

18. Redmond A, Burns J, Ouvrier R (2008) Factors that Influence HealthRelated Quality of Life in Australian Adults with Charcot-Marie-Tooth Disease. Neuromuscular Disorders 18(8): 619-625.

\section{Your next submission with Juniper Publishers will reach you the below assets}

- Quality Editorial service

- Swift Peer Review

- Reprints availability

- E-prints Service

- Manuscript Podcast for convenient understanding

- Global attainment for your research

- Manuscript accessibility in different formats

( Pdf, E-pub, Full Text, Audio)

- Unceasing customer service

Track the below URL for one-step submission https://juniperpublishers.com/online-submission.php 